\title{
Preliminary Analysis on the Solar Burst Type III and the Effect of the Magnetic Reconnection
}

\author{
Nurulhazwani Husien ${ }^{1}$, Z. S. Hamidi ${ }^{1}$, N. N. M. Shariff ${ }^{2}$, C.Monstein $^{3}$ \\ ${ }^{1}$ School of Physics and Material Sciences, Faculty of Sciences, MARA University of Technology, \\ 40450, Shah Alam, Selangor, Malaysia \\ ${ }^{2}$ Academy of Contemporary Islamic Studies (ACIS), MARA University of Technology, 40450, Shah \\ Alam, Selangor, Malaysia \\ ${ }^{3}$ Institute of Astronomy, Wolfgang-Pauli-Strasse 27, Building HIT, Floor J, \\ $\mathrm{CH}-8093$ Zurich, Switzerland \\ E-mail address: ${ }^{1}$ zetysh@salam.uitm.edu.my
}

Keywords: Sun; solar burst; III; radio region; X-ray region; solar flare; active region

\begin{abstract}
From the data from a BLEIN Callisto site, we aim to provide a comprehensive description of the synopsis formation and dynamics of a a single solar burst type III and magnetic reconnection effect. The data above is the solar radio burst type iii occurred on 10th September 2005 between 05:44 UT till 06:00 UT.This eruption has started since 5:55 UT with a formation of type III solar burst. The wave emission process of solar radio burst type III from magnetic reconnection region in a solar flare were investigated by using a two-dimensional, that are electromagnetic and relativistic particle-in-cell code. The solar radio burst type III initially impose into two plasma populations : background dense plasma and hot electrons that can be generated by the magnetic reconnection process in a solar flare. The conversion of the energy stored in the magnetic field by a process called the magnetic reconnection released the energy in the solar flares and related phenomena. By the launching the e-CALLISTO network, its prove the existence of the magnetic reconnection on the surface of the sun in radio region.
\end{abstract}

\section{INTRODUCTION}

The Sun is the nearest star in our galaxy. The distance this star from our Earth is $149,600,000$ $\mathrm{km}$. However the biggest star from the Earth take about 5000 light years from our Earth. The structure of the Sun consists of prominence, granulation, sunspot, corona , chromospheres, photosphere, convective zone, radiative zone, and core. Corona is the most active region and beyond has a temperature millions of degrees which is still considered as mysteries properties. Usually the solar radio burst occurs at the surface of the corona. Under certain circumstances, solar burst type III plays an important rule to understand of solar accelerated electron beams. It is a propagating beams of nonthermal electrons in the solar atmosphere and the solar system [1,2,3]. Electrons are regularly accelerated to near-relativistic energies by unstable magnetic field of solar atmosphere [4]. The frequency of drift rate is the change of frequency in time. The starting frequency of type III burst varies dramatically from burst to burst. During large solar flare type iii burst can starts at frequency in GHz. Typically type III bursts will start at 10s or 100s of $\mathrm{MHz}$ and can start at even lower frequencies [5]. Some type III burst will only exist at high frequencies above $100 \mathrm{MHz}[6]$. These solar type III radio emissions is dominant a few days before solar flare and Coronal Mass Ejections explosion [7,8,9].

Type III bursts trace electron streams as they propagate along open field lines from flaring regions near the Sun into the interplanetary medium.In general, solar radio burst type III solar burst is the most the most common type [10] with range of frequency from $500-10 \mathrm{MHz}[11,12,13]$. This emission is probably from a part of the electron population that remains trapped in closed magnetic loops [14]. Usually, a fast drift (type III) solar radio bursts are synchronized in time with solar flares [15]. A previous study has shown that the type III are generated in a weak-field region comes from the absence or low degree of circular polarization of the bursts [16]. Langmuir waves 
active region radio emissions is believed to be a main subject that relevant with a type III burst $[17,18,19,20,21]$. These forces drive the plasma to a state unstable to the growth the beam-plasma interactions, is believed to generating these waves [22,23]. This type is very synonymous at the meter and decimeter wavelengths [24,25]. Early stage of solar flares may indicate that open field lines are an essential part of models for energy release by magnetic fields [26,27].

The conversion of the energy stored in the magnetic field by a process called the magnetic reconnection released the energy in the solar flares and related phenomena. Commonly the solar radio burst type III will also produce solar radio burst type II. This solar radio burst occurs due to magnetic reconnection. Magnetic reconnection is the primary energy that release the heats plasma and accelerates particles. It is the key link in the process of flare triggering. It is also the process by which magnetic lines of force break and re-join in a lower-energy configuration, which magnetic energy converted into plasma kinetic energy. The corona is a good conductive medium. Therefore, it still has a finite resistivity. The magnetic energy can also be released in the diffusion process. Magnetic reconnection has been established to play an important role in these processes. The magnetic reconnection changes the topology of the field surrounding the flux rope and assist reduce the magnetic tension force that bind the flux rope to the solar surface, hence enhance acceleration of the expulsion. Detailed analysis of the Sun in radio and x-ray region to understand the distribution of high and low energy [28,29,30,31]. We will highlight the solar flare and solar bursts in both electromagnetic radiation.

\section{SOLAR FLARE OBSERVATION}

In this section will discuss about the network used to obtain the data about the solar radio burst type III. There are a lot networks that can be used to obtain the data of solar flares such as e CALLISTO and NOAA. During a major space weather event which includes a burst of solar [32,33,34]. Compact Astronomical Low cost, Low frequency Instrument for Spectroscopy and Transportable Observatory (CALLISTO) from BLEIN with the 7 meter dish telescope at ETH, Zurich is being used to monitor the solar burst. [35,36]. We also have constructed a log-periodic antenna is a broadband, multi-element, unidirectional, narrow-beam antenna that has impedance and radiation characteristics that are regularly repetitive as a logarithmic function of the excitation frequency $[34,37,38,39,40]$. The Log Periodic Dipole Antenna has been constructed from 45 - 870 $\mathrm{MHz}[41,42,43,44]$. The CALLISTO spectrometer is a low-cost radio spectrometer used to monitor metric and decametric radio bursts [45,46,47,48,49]. We select the range of $150 \mathrm{MHz}$ till $900 \mathrm{MHz}$ for this data [50,51,52]. This range has a very minimum interference at Blein, Switzerland site $[53,54]$. Selected the data from the $150 \mathrm{MHz}$ till $900 \mathrm{MHz}$ region seems this is the best range with a very minimum of Radio Frequency Interference (RFI) [54,55,56,57,58]. The next section will highlight the detailed analysis of solar flares in an X-ray and radio region to evaluate the distribution of high and low energy [41]. The instrumental parameters used in CALLISTO were stated in the table below. 
Table 1: The specification of CALLISTO spectrometer

\begin{tabular}{|c|l|}
\hline Parameter & \multicolumn{1}{|c|}{ Specification } \\
\hline Frequency range & \multicolumn{1}{c|}{$45.0 \mathrm{MHz}$ to $870 \mathrm{MHz}$} \\
\hline Frequency resolution & $62.5 \mathrm{KHz}$ \\
\hline Radiometric bandwith & $300 \mathrm{KHz} /-3 \mathrm{Db}$ \\
\hline Dynamic range & $\begin{array}{l}-120 \mathrm{dBm} \text { to }-20 \mathrm{dBm}(\text { depending on gain } \\
\text { voltage) }\end{array}$ \\
\hline Sensitivity & $25 \mathrm{Mv} / \mathrm{Db}+/-1 \mathrm{Mv} / \mathrm{dB}$ \\
\hline Noise figure & $<10 \mathrm{dBm}$ \\
\hline Sampling frequency & $\begin{array}{l}\text { Internal clock } 800 \mathrm{~s} / \mathrm{sec} \text { max, external clock } \\
1000 \mathrm{~s} / \mathrm{sec} \text { max }\end{array}$ \\
\hline Number of channels & 1 to 500, nominal 200 frequency per sweep \\
\hline Supply & $12 \mathrm{~V}+/-2 \mathrm{~V} / 225 \mathrm{Ma}$ \\
\hline Weight & $\sim 800$ grams \\
\hline Dimensions & $110 \mathrm{~mm} \times$ 80mm $x$ 205mm \\
\hline Material cost & $<200 \$$ ( material only $)$ \\
\hline Input & $\begin{array}{l}3 \text { configuration files (config, frequency, } \\
\text { scheduler) }\end{array}$ \\
\hline Output & 2 files (FITS-file and logfile) \\
\hline
\end{tabular}

\section{RESULTS AND ANALYSIS}

Solar burst type III rapidly drift from high to low frequencies. It may exhibits harmonics and sometimes accompany the flash phase of large flares. The data above is the solar radio burst type iii occurred on 10 ${ }^{\text {th }}$ September 2005 between 05:44 UT till 06:00 UT. This data were detected by the antenna BLEN5M ( Bleien 5m parabola) model QM. The peak was between 05:54 UT till 05:56 UT. The wave emission process of solar radio burst type III from magnetic reconnection region in a solar flare were investigated by using a two-dimensional, that are electromagnetic and relativistic particle-in-cell code. The solar radio burst type III initially impose into two plasma populations : background dense plasma and hot electrons that can be generated by the magnetic reconnection process in a solar flare. The hot electron plasmas lead to generation of Langmuir waves and generated Langmuir waves can be converted to electromagnetic waves (solar type III radio burst) through the direct linear made conversion process. The emission process of radio burst type III from a magnetic reconnection region in the solar flare were investigated by using two-dimensional, electromagnetic and relativistic particle-in-cell. 


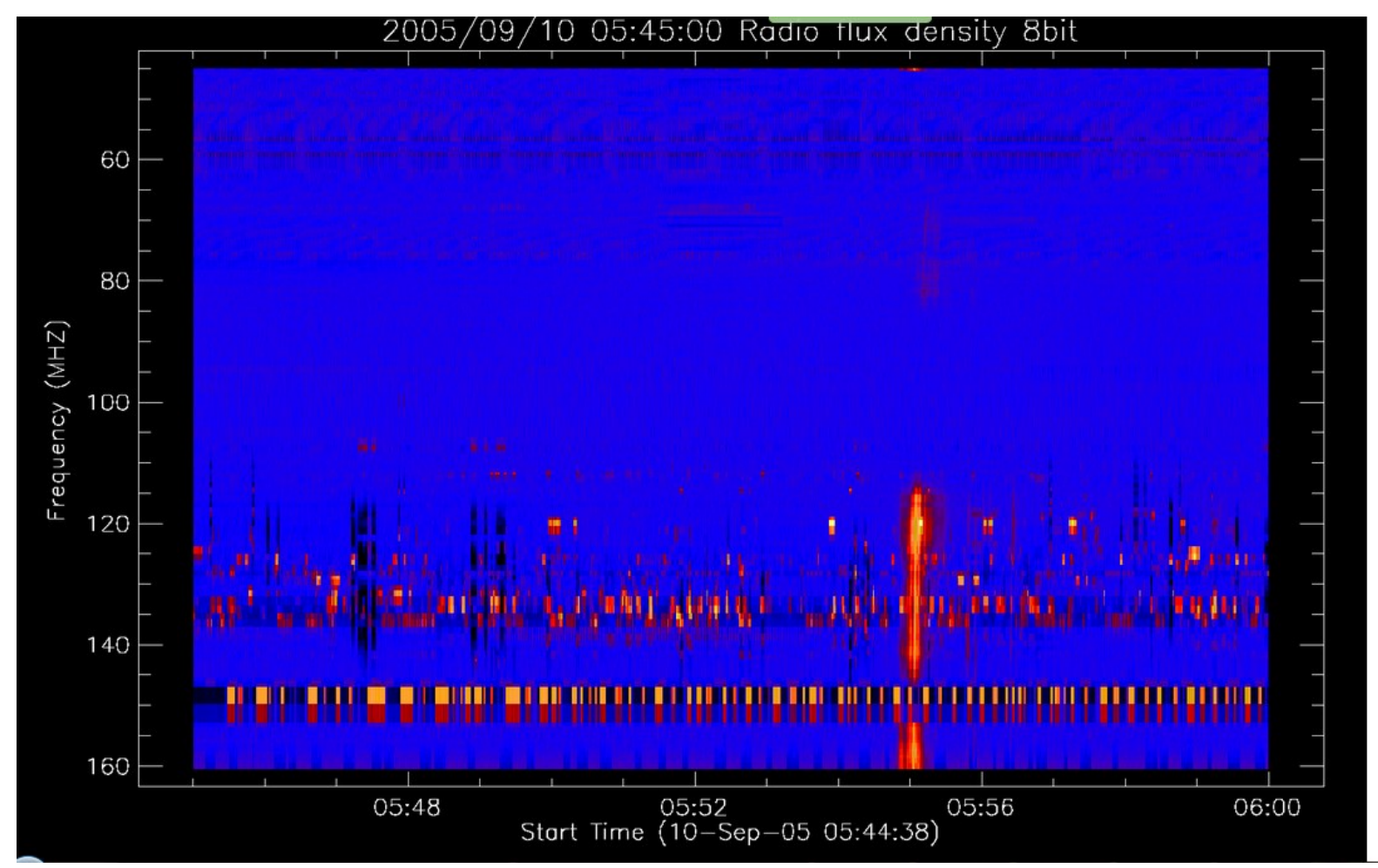

Figure 1: The single solar radio burst type III at 5:55 UT (Credited to: E-Callisto network (BLEIN7M))

Reconnection of magnetic fields on the surface of the sun drive the biggest explosions in our solar system. The magnetic reconnection that produced solar radio burst can be detected by the e CALLISTO. The reconnected magnetic fields were proved by launching the Yohkoh satellite. The scientific objective was to observe the energetic phenomena taking on the Sun, specifically solar flares in X-ray and gamma ray. There were four instruments on this satellite to detect the energetic emissions from the Sun. they are Bragg Crystal Spectrometer (BCS), Wide Band Spectrometer (WBS), Soft X-ray Telescope (SXT) and Hard X-Ray Telescpope (HXT).

\section{CONCLUDING REMARKS}

By the launching the e-CALLISTO network, its prove the existence of the magnetic reconnection on the surface of the sun in radio region. The solar radio burst type III rapidly drifts from high to low frequencies. The hot electron plasmas cause the Langmuir waves and generated Langmuir waves can be converted to electromagnetic waves (solar type III radio burst) through the direct linear mode conversion process.

\section{Acknowledgement}

We are grateful to CALLISTO network; STEREO, LASCO, SDO/AIA, NOAA and SWPC make their data available online. This work was partially supported by the $600-\mathrm{RMI} / \mathrm{FRGS} 5 / 3$ (135/2014), 600-RMI/RACE 16/6/2(4/2014and 600- RMI/RAGS 5/3 (121/2014) UiTM grants, Universiti Teknologi MARA and Kementerian Pendidikan Malaysia. Special thanks to the National Space Agency and the National Space Centre for giving us a site to setup this project and support this project. Solar burst monitoring is a project of cooperation between the Institute of Astronomy, ETH Zurich, and FHNW Windisch, Switzerland, MARA University of Technology and University of Malaya. The research has made use of the National Space Centre Facility and a part of an initiative of the International Space Weather Initiative (ISWI) program. 


\section{Biography}

Dr Zety Sharizat Hamidi is currently a senior lecturer and focused in Solar Astrophysics research specifically in radio astrophysics at the School of Physics and Material Sciences, Faculty of Sciences, MARA University of Technology, 40450, Shah Alam, Selangor, Malaysia. Involve a project under the International Space Weather Initiative (ISWI) since 2010.

Nurulhazwani Husien is an undergraduate Physics student at the School of Physics and Material Sciences, Faculty of Sciences, MARA University of Technology, 40450, Shah Alam, Selangor, Malaysia.

Dr Nur Nafhatun Md Shariff is a senior lecturer in Academy of Contemporary Islamic Studies (ACIS), MARA University of Technology, 40450, Shah Alam, Selangor, Malaysia.Her current research is more on sustainability; environmental aspect. She is looking forward for cross-field research, i.e. solar astrophysics, light pollution measurement (mapping) and religious studies.

C.Monstein is a senior Engineer at Institute of Astronomy, Wolfgang-Pauli-Strasse 27, Building HIT, Floor J, CH-8093 Zurich, Switzerland and one of the researchers who initiated the CALLISTO system around the world.

\section{References}

[1] Z. Hamidi, Z. Abidin, Z. Ibrahim, C. Monstein, N. Shariff, M. Sabaghi, The Beginning Impulsive of Solar Burst Type IV Radio Emission Detection Associated with M Type Solar Flare, International Journal of Fundamental Physical Sciences 2 (2012).

[2] Z. Hamidi, N. Shariff, C. Monstein, Disturbances of Solar Eruption From Active Region AR1613, (2014).

[3] Z. Hamidi, N. Shariff, Detailed Investigation of a Moving Solar Burst Type IV Radio Emission in on Broadband Frequency, International Letters of Chemistry, Physics and Astronomy 7 (2014) 30-36.

[4] Z. Hamidi, Z. Abidin, Z. Ibrahim, C. Monstein, N. Shariff, Signal Detection Performed by Log Periodic Dipole Antenna (LPDA) in Solar Monitoring, International Journal of Fundamental Physical Sciences (2012).

[5] H. Aurass, Coronal Physics from Radio and Space Observations, in: I.G. Trottet (Ed.), Lecture Notes in Physics, Springer, Berlin, 1997.

[6] A.D. Fokker, Type IV Solar Radio Emission, Space Science Reviews 2 (1963) 70-90.

[7] C.W. Young, C.L. Spencer, G.E. Moreton, J.A. and Roberts, Astrophys. J. 133 (1961).

[8] Ellis, Australian J.Phys. 22 (1969) 167.

[9] D.J. McLean, a.N.R. Labrum, Solar Radiophysics, Cambridge University Press, Cambridge, 1985.

[10] J.P. Wild, Smerd S.F., and Weiss, A.A., Solar Burst, Ann. Rev. Astron. Astrophysics 1 (1963) 291-366.

[11] Z. Hamidi, N. Shariff, The Propagation of An Impulsive Coronal Mass Ejections (CMEs) due to the High Solar Flares and Moreton Waves, (2014).

[12] Z. Hamidi, U. Ibrahim, U.F. Salwa, Z. Abidin, Z. Ibrahim, N. Shariff, Theoretical Review of Solar Radio Burst III (SRBT III) Associated With of Solar Flare Phenomena, International Journal of Fundamental Physical Sciences 3 (2013). 
[13] Z. Hamidi, N. Shariff, C. Monstein, First Light Detection of A Single Solar Radio Burst Type III Due To Solar Flare Event, (2014).

[14] G.A. Dulk, Type III solar radio bursts at long wavelengths, in: R. Stone, E. Weiler, M. Goldstein (Eds.), Geophys. Monogr., 2000.

[15] G. Swarup, P.H. Stone, A. Maxwell, ApJ 131 (1960).

[16] Z. Hamidi, N. Shariff, C. Monstein, Scenario of Solar Radio Burst Type III During Solar Eclipse on 14 th November 2012, (2014).

[17] G.B.a.L. Gelfreikh, B. I. , Soviet Astron. 23 (1979).

[18] P. Lantos, Sol. Phys. 22 (1972).

[19] A. Vourlidas, Bastian, T. S., Nitta, N., and Aschwanden, M. J., Sol. Phys. 163 (1996).

[20] E.Y. Zlotnik, Soviet Astron. 12 (1968).

[21] V.V. Zheleznyakov, Radio Emission of the Sun and Planets (1970).

[22] Z. Hamidi, N. Shariff, C. Monstein, W.W. Zulkifli, M. Ibrahim, N. Arifin, N. Amran, An Xray Observations of A Gradual Coronal Mass Ejections (CMEs) on 15th April 2012, International Letters of Chemistry, Physics and Astronomy 8 (2014) 13-19.

[23] Z. Hamidi, N. Shariff, C. Monstein, Statistical Study of Nine Months Distribution of Solar Flares, (2014).

[24] Z. Hamidi, Z. Abidin, Z. Ibrahim, C. Monstein, N. Shariff, Combined Investigations of Solar Bursts Type III and V, International Journal of Fundamental Physical Sciencea 2 (2012) 3.

[25] Z. Hamidi, N. Shariff, Observations of Different Type of Bursts Associated with M 6.3 Solar Flares, International Letters of Chemistry, Physics and Astronomy 4 (2014) 29-36.

[26] S.M. White, Solar Radio Bursts and Space Weather, Asian Journal of Physics 16 (2007) 189207.

[27] Z.S. Hamidi, N.N.M. Shariff, Chronology of Formation of Solar Radio Burst Types III and V Associated with Solar Flare Phenomenon on 19th September 2011 International Letters of Chemistry, Physics and Astronomy 5 (2014) 32-42.

[28] Z.S. Hamidi, N.N.M. Shariff, M.F. Ali, C. Monstein, W.N.A.W. Zulkifli, M.B. Ibrahim, N.S. Arifin, N.A. Amran, The Correlation between Solar Flare Phenomena in an X-ray Region and Radio Flux Measurement from January to September 2010, International Letters of Chemistry,Physics \& Astronomy 9 (2014) 84-92.

[29] Z.S. Hamidi, N.N.M. Shariff, F.N.Z. Ulum, Z.Z. Abidin, Z.A. Ibrahim, Time Series Analysis of Variance of Sunspots in January till September 2010 and Correlation with Sunspots Areas International Journal of Astronomy 5 (2012) 101-106.

[30] Z. Hamidi, Probability of Solar Flares Turn Out to Form a Coronal Mass Ejections Events Due to the Characterization of Solar Radio Burst Type II and III, International Letters of Chemistry, Physics and Astronomy 16 (2014) 85.

[31] Z. Hamidi, C. Monstein, N. Shariff, Radio Observation of Coronal Mass Ejections (CMEs) Due to Flare Related Phenomenon on 7 th March 2012, (2012).

[32] Z. Hamidi, N. Shariff, Enormous Eruption of 2.2 X-class Solar Flares on 10 th June 2014, (2014).

[33] Z. Hamidi, N. Shariff, C. Monstein, Understanding Climate Changes in Malaysia Through Space Weather Study, International Letters of Natural Sciences (2014). 
[34] Z. Hamidi, N. Shariff, The Mechanism of Signal Processing of Solar Radio Burst Data in ECALLISTO Network (Malaysia), International Letters of Chemistry, Physics and Astronomy (2014).

[35] Z. HAMIDI, N. SHARIFF, Z. ABIDIN, Z. IBRAHIM, C. MONSTEIN, E-Callisto Collaboration: Some Progress Solar Burst Studies Associated with Solar Flare Research Status in Malaysia, Malaysian Journal of Science and Technology Studies 9 (2013) 15-22.

[36] Z.S. Hamidi, N. Shariff, Z. Abidin, Z. Ibrahim, C. Monstein, Coverage of Solar Radio Spectrum in Malaysia and Spectral Overview of Radio Frequency Interference (RFI) by Using CALLISTO Spectrometer from $1 \mathrm{MHz}$ to $900 \mathrm{MHz}$, Middle-East Journal of Scientific Research 12 (2012) 6.

[37] Z.S.Hamidi, N.N.M.Shariff, Evaluation of Signal to Noise Ratio (SNR) of Log Periodic Dipole Antenna (LPDA) Business Engineering and Industrial Applications Colloquium 2013, IEEE, Langkawi, Malaysia, 2013, pp. 434-438.

[38] Z. Hamidi, N. Shariff, Determination of Flux Density of the Solar Radio Burst Event by Using Log Periodic Dipole Antenna (LPDA), International Letters of Chemistry, Physics and Astronomy 7 (2014) 21-29.

[39] Z. Hamidi, N. Shariff, C. Monstein, The Different Between the Temperature of the Solar Burst at the Feed Point of the Log Periodic Dipole Antenna (LPDA) and the CALLISTO Spectrometer, (2014).

[40] N. Hashim, Z. Abidin, U. Ibrahim, R. Umar, M. Hassan, Z. Rosli, Z. Hamidi, Z. Ibrahim, Radio Astronomy in Malaysia: Current Status and Outreach Activities, Astronomical Society of the Pacific Conference Series, 2011, pp. 355.

[41] Z.S. Hamidi, Z. Ibrahim, Z. Abidin, M. Maulud, N. Radzin, N. Hamzan, N. Anim, N. Shariff, Designing and Constructing Log Periodic Dipole Antenna to Monitor Solar Radio Burst: eCallisto Space Weather, International Journal of Applied Physics and Mathematics 2 (2011) 3.

[42] Z. Hamidi, N. Shariff, C. Monstein, Evaluation of Spectral Overview and Radio Frequency Interference (RFI) Sources at Four Different Sites in CALLISTO Network at the Narrow Band Solar Monitoring Region, (2014).

[43] Z.S. Hamidi, N.N.M. Shariff, C. Monstein, Z.A. Ibrahim, Space Weather: The Significance of e-CALLISTO (Malaysia) As One of Contributor of Solar Radio Burst Due To Solar Activity, International Letters of Chemistry, Physics and Astronomy 7 (2014) 37-44.

[44] Z.S. Hamidi, N.N.M. Shariff, Z.A. Ibrahim, Z.Z. Abidin, SOLAR STUDIES IN RADIO EMISSION AND OPTICAL PHOTOMETRY, University of Malaya Publisher, 2013.

[45] Z.S.Hamidi, S. Chumiran, A. Mohamad, N. Shariff, Z. Ibrahim, N. Radzin, N. Hamzan, N. Anim, A. Alias, Effective temperature of the sun based on log periodic dipole antenna performance in the range from $45 \mathrm{Mhz}$ to $870 \mathrm{Mhz}$, American Journal of Modern Physics 2 (2013) 4.

[46] Z.S.Hamidi, Z. Abidin, Z. Ibrahim, N. Shariff, C. Monstein, Modification and Performance of Log Periodic Dipole Antenna, International Journal of Engineering Research and Development 3 (2012) 36-39.

[47] Z.S.Hamidi, Z. Abidin, Z. Ibrahim, C. Monstein, N. Shariff, Signal Detection Performed by Log Periodic Dipole Antenna (LPDA) in Solar Monitoring, International Journal of Fundamental Physical Sciences 2 (2012) 32-34. 
[48] Z.S.Hamidi, N.M.Anim, N. N.S.Hakimi, N.Hamzan, A.Mokhtar, N.Syukri, S.Rohizat, I.Sukma, Z.A. Ibrahim, Z.Z.Abidin, N.N.M.Shariff, C.Monstein, Application of Log Periodic Dipole Antenna (LPDA) in Monitoring Solar Burst at Low Region Frequencies Region International Journal of Fundamental Physical Sciences 2 (2012) 4.

[49] Z.S.Hamidi, N.N.M. Shariff, Determination of Isotropic Source Spectral Power of the Log Periodic Dipole Antenna (LPDA), International Journal of Science and Mathematics 2 (2014) 3.

[50] Z.S.Hamidi, Z. Abidin, Z. Ibrahim, N. Shariff, Indication of radio frequency interference (RFI) sources for solar burst monitoring in Malaysia, ICPAP 2011, AIP Publisher, Indonesia, 2012, pp. 6 .

[51] Z.S. Hamidi, N.N.M. Shariff, C. Monstein, High Time Resolution Observation of Solar Radio of A Group Type III And U Burst Associated of Solar Flares Event, The International Journal of Engineering 1 (2012) 3.

[52] Z. Hamidi, N. Shariff, C. Monstein, W.W. Zulkifli, M. Ibrahim, N. Arifin, N. Amran, Observation of the Radio Frequency Interference (RFI) at the National Space Centre, Malaysia, International Letters of Natural Sciences (2014).

[53] Z.S. Hamidi, Z.Z. Abidin, Z.A. Ibrahim, N.N.M. Shariff, U.F.S.U. Ibrahim, R. Umar, Preliminary analysis of investigation Radio Frequency Interference (RFI) profile analysis at Universiti Teknologi MARA, IEEE, 2011, pp. 311-313.

[54] R. Umar, Z. Abidin, Z. Ibrahim, N. Gasiprong, K. Asanok, S. Nammahachak, S. Aukkaravittayapun, P. Somboopon, A. Prasit, N. Prasert, The Study of Radio Frequency Interference (RFI) in Altitude Effect on Radio Astronomy In Malaysia And Thailand, Middle East Journal of Scientific Research 14 (2013).

[55] Z.S.Hamidi, N.N.M.Shariff, R.Umar, Influence Factors of Radio Frequency Interference (RFI) for Solar Radio Astronomy Purpose at National Space Centre, Malaysia Thailand Journal of Physics 3 (2012) 6.

[56] R. Umar, Z.Z. Abidin, Z.A. Ibrahim, M.S.R. Hassan, Z. Rosli, Z.S. Hamidi, Population density effect on radio frequencies interference (RFI) in radio astronomy, AIP Conference Proceedings 1454 (2012) 39.

[57] N. Anim, Z. Hamidi, Z. Abidin, C. Monstein, N. Rohizat, Radio frequency interference affecting type III solar burst observations, 2012 NATIONAL PHYSICS CONFERENCE:(PERFIK 2012), American Institute of Physics, 2013, pp. 82-86.

[58] Z. Hamidi, N. Shariff, C. Monstein, Comparison of the Radio Frequency Interference (RFI) in the Region of Solar Burst Type III Data At Selected CALLISTO Network, International Letters of Chemistry, Physics and Astronomy 10 (2014) 38-45. 